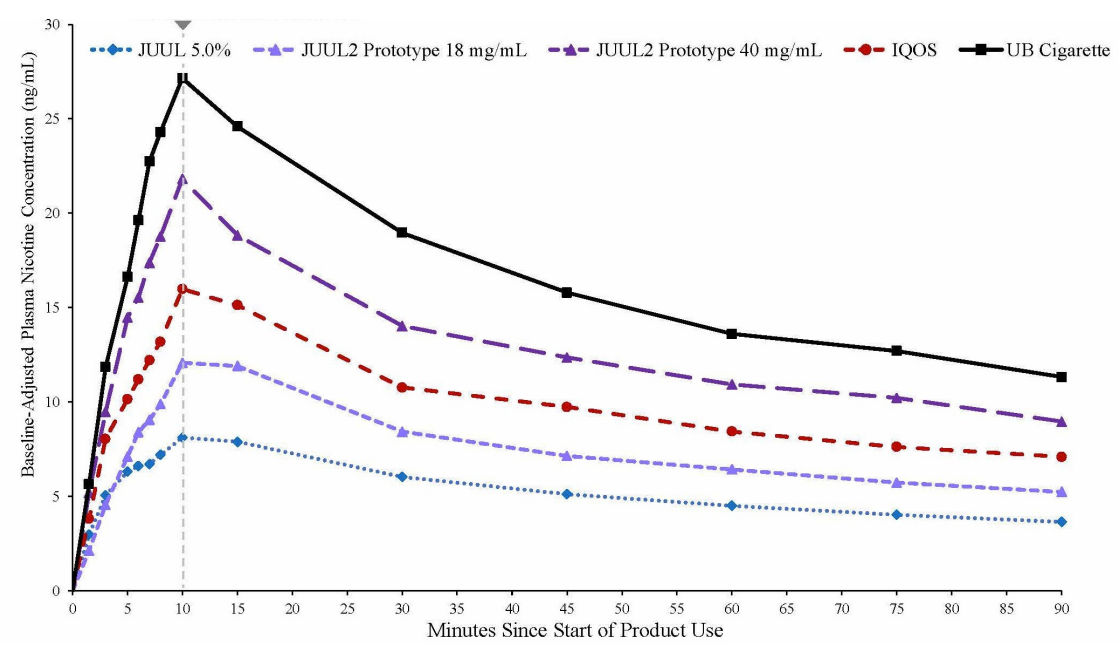

\title{
Pharmacokinetic and Subjective Assessment of the JUUL System, Prototype JUUL2 Electronic Nicotine Delivery System in Two Nicotine Concentrations, IQOS and Combustible Cigarette
}

\author{
Nicholas Goldenson ${ }^{1}$, Joey Chen ${ }^{1}$, Saul Shiffman ${ }^{2}$ \\ 1 JUUL Labs \\ 2 University of Pittsburgh \\ Funding: This study was funded by Juul Labs, Inc. \\ Potential competing interests: Authors NIG, EMA and JC are full-time employees of Juul Labs, Inc. SS is a senior advisor to \\ PinneyAssociates, Inc. PinneyAssociates provides consulting services on tobacco harm reduction on an exclusive basis to Juul Labs, \\ Inc. Within the last two years, PinneyAssociates has consulted for British American Tobacco and Reynolds American Inc and \\ subsidiaries on tobacco harm reduction.
}

\section{Abstract}

RATIONALE: Electronic nicotine delivery systems (ENDS) and heated tobacco products (HTP) are noncombustible alternatives for adult smokers. Evidence suggests sufficient nicotine delivery is necessary to facilitate switching away from smoking; nicotine delivery varies across ENDS within limited nicotine concentrations.

OBJECTIVES: To assess the nicotine delivery and subjective effects of currently-marketed US JUUL System ("JUUL") ENDS, prototype JUUL2 ENDS in two nicotine concentrations, IQOS HTP and combustible cigarettes.

METHODS: Adult smokers $(\mathrm{N}=40)$ completed a 5-arm cross-over product-use laboratory confinement 
study. Nicotine PK and subjective effects were assessed following use of: (1) JUUL 59mg/mL nicotine; (2) JUUL2 Prototype 18mg/mL; (3) JUUL2 Prototype 40mg/mL; (4) IQOS HTP 18mg/g; (5) usual brand (UB) cigarette, each evaluated during ad libitum (10 minutes) and controlled (5 minutes, 10 standardized puffs) use.

RESULTS: Nicotine delivery was greatest for UB cigarette, followed by JUUL2 Prototype $40 \mathrm{mg} / \mathrm{mL}$, IQOS, JUUL2 Prototype $18 \mathrm{mg} / \mathrm{mL}$, and JUUL $59 \mathrm{mg} / \mathrm{mL}$. Nicotine delivery from JUUL2 Prototype $18 \mathrm{mg} / \mathrm{mL}$ was significantly greater than JUUL $59 \mathrm{mg} / \mathrm{mL}$ after ad libitum use. JUUL products were significantly more satisfying and effective at reducing craving than IQOS. JUUL2 Prototype $40 \mathrm{mg} / \mathrm{mL}$ was significantly more aversive than other JUUL products.

CONCLUSIONS: Currently-marketed JUUL $59 \mathrm{mg} / \mathrm{mL}$ and prototype JUUL ENDS products were rated higher than IQOS on subjective measures associated with switching away from smoking. The JUUL2 Prototype $40 \mathrm{mg} / \mathrm{mL}$ produced aversive responses, and requires modifications to be a viable product for adult smokers. Nicotine delivery and subjective responses to JUUL2 Prototype $18 \mathrm{mg} / \mathrm{mL}$ suggest a product based on this prototype may facilitate increased switching among adult smokers.

\section{INTRODUCTION}

The harms of cigarette smoking primarily result from exposure to the toxicants and carcinogens produced by the combustion of tobacco, rather than from nicotine-the principal constituent that maintains smoking (1-3). Noncombustible alternative nicotine-delivery products such as electronic nicotine delivery systems (ENDS) and heat-not-burn or heated tobacco products (HTP) have the potential to benefit public health by helping smokers who would not otherwise quit to switch completely away from cigarettes (3). Although both ENDS and HTP deliver nicotine without combusting tobacco, and thus expose smokers to lower levels of harmful chemicals than cigarettes (4), they use distinct technologies: ENDS aerosolize an eliquid (typically a mixture of glycerol and/or propylene glycol) containing nicotine (5), whereas HTP typically heat tobacco leaf to a temperature below that required to combust tobacco but sufficient to release a nicotine-containing aerosol (6).

Prior studies have compared the JUUL System ENDS ("JUUL") and IQOS HTP, with mixed results: a recent study of smokers who had almost completely transitioned to ENDS found that the nicotine delivery of JUUL $59 \mathrm{mg} / \mathrm{mL}$ exceeded that of IQOS, and that JUUL reduced craving for cigarettes more effectively than IQOS (7). In contrast, two previous studies did not find significant differences in nicotine delivery or subjective effects between JUUL and IQOS among adult smokers who did not use ENDS (8, 9). Hence, it is unclear if differences exist in the nicotine PK and subjective effects of JUUL and IQOS.

Public health authorities and regulatory agencies recognize that noncombustible nicotine-delivery products must effectively deliver nicotine and produce satisfying effects to successfully convert adult smokers (1012). Recent data supports this concept: a randomized clinical trial that manipulated ENDS nicotine 
concentration found that smokers assigned to the highest nicotine concentration $(36 \mathrm{mg} / \mathrm{mL})$ experienced the greatest reduction in cigarette smoking and concomitant exposure to smoking-related toxicants, and the authors noted that ENDS must deliver sufficient nicotine to facilitate switching in smokers (13). Consistent with this, an observational study (14) found that UK smokers using JUUL with nicotine concentrations below $20 \mathrm{mg} / \mathrm{mL}$ mandated by the European Union Tobacco Products Directive (15) were less likely to switch away from smoking than US and Canadian smokers using JUUL with 59 or $35 \mathrm{mg} / \mathrm{mL}$ nicotine concentration with demonstrated higher nicotine delivery (16).

ENDS are a highly heterogeneous category of products, consisting of both closed systems and open systems with a wide range of customizable options: the nicotine delivery of ENDS is influenced by a combination of factors beyond the nicotine concentration in the e-liquid, including device characteristics that affect aerosol production and user behavior (17). Given the importance of sufficient nicotine delivery in supporting switching away from smoking, research has explored factors other than nicotine concentration that may modulate nicotine delivery from ENDS and subjective effects.

ENDS with greater device power produce more aerosol and result in more rewarding subjective effects (18-22). A controlled laboratory study that manipulated several ENDS device and e-liquid characteristics found that ENDS that produce greater aerosol mass more effectively delivered nicotine and were rated significantly higher on measures of product liking (23). The current study evaluated prototype JUUL ENDS products ("JUUL2") that aerosolize more e-liquid and concomitantly deliver greater aerosol mass, and more nicotine, with the aim of producing a usage experience that facilitates smokers switching away from cigarettes.

The primary aims of the current residential laboratory study were to: (1) evaluate the nicotine PK and subjective effects of currently-marketed JUUL and prototype JUUL2 ENDS products compared to IQOS and combustible cigarettes among adult smokers; and (2) assess nicotine PK and subjective responses to prototype JUUL2 ENDS with two different nicotine concentrations (18 and $40 \mathrm{mg} / \mathrm{mL}$ ) in order to inform development of products that could help smokers switch away from cigarettes.

\section{METHODS}

\section{Participants}

Healthy, adult cigarette smokers who were not intending to quit were recruited in the Montreal, Canada metropolitan area in 2021. Inclusion criteria were: (1) 22-65 years of age; (2) cigarette smoking for $\geq 12$ months prior to screening; (3) currently smoking an average of $\geq 10$ nonmentholated cigarettes per day (verified by urine cotinine $\geq 200 \mathrm{ng} / \mathrm{mL}$ and exhaled carbon monoxide $>10 \mathrm{ppm}$ ). Exclusion criteria were: (1) use of any prescription smoking cessation medications (e.g., varenicline, bupropion) within 30 days prior to study Day $1 ;$ (2) plan to quit smoking during the study or postpone a quit attempt in order to participate in the study; (3) medical (including positive COVID-19 test) or psychiatric condition that could interfere with conduct of study or jeopardize participant safety; (4) positive urine screen for drugs of abuse or positive alcohol breath test; (5) pregnancy for females. There were no eligibility criteria regarding use of ENDS, other noncigarette tobacco products or nicotine replacement therapy. 
All participants provided written informed consent and were compensated for their participation. The Advarra Institutional Review Board (https://www.advarra.com/review-services/institutional-review-board/) approved the study protocol and the study was conducted in accordance with the Declaration of Helsinki and the TriCouncil Policy Statement (Canada).

\section{Design}

The study utilized an open-label, randomized, crossover within-subjects design. Participants were randomly assigned to one of five product sequences based on a block randomization scheme.

\section{Procedure}

Eligible participants were confined to a clinical residential research facility for the duration of the study, allowing for staff monitoring of compliance to protocol. Prior to the first day of product use, participants completed a product training and familiarization session for the JUUL products and IQOS in which they watched a training video and then used each of the JUUL and IQOS test products for 10 minutes ad libitum; use of successive products was separated by 15 minutes. Participants were also instructed how to perform the controlled puffing sequence (i.e., inhale for 3 seconds, remove the product from mouth and inhale for an additional 3 seconds before exhaling; repeated every 30 seconds for a total of 10 puffs [5 minutes total]) by watching a training video and then practicing the controlled puffing sequence using JUUL 59 $\mathrm{mg} / \mathrm{mL}$. Participants who did not tolerate or were unwilling to use any of the study products during the product familiarization period or were unable to successfully perform the controlled puffing sequence by reducing the weight of the pod by $20-60 \mathrm{mg}$ (to standardize exposure) in up to three attempts were deemed ineligible. Following completion of the familiarization period participants were allowed to smoke their UB cigarettes ad libitum for four hours, ending at least 12 hours prior to the first day of product use. During the five product-use days, tobacco/nicotine product use was only permitted during the ad libitum and controlled product use sessions. The experimental procedures for the product use sessions were identical on each of the five product-use days. Participants first used their randomly-assigned test product during a 10-minute ad libitum session (preceded by $\geq 12$ hours of nicotine/tobacco product abstinence) and then, at least 6 hours later, during a controlled use session (10 standardized puffs) that lasted five minutes. It is important to note the difference in the duration of the ad libitum and controlled use sessions (10 vs. 5 minutes) when interpreting PK parameters in these two use conditions.

In both ad libitum and controlled sessions, blood samples were collected five-minutes before and 1.5, 3, 5, $6,7,8,10,15,30$, and 60 minutes after the start of product use. Given the longer duration of product use in the ad libitum use sessions, additional blood draws were taken at 45, 75, and 90 minutes. PK profiles with multiple missing blood draws were excluded.

In all sessions, subjective responses to use of study products were assessed with the modified Product Evaluation Scale (MPES; (24) 30 minutes following the start of product use, after the 30-minute blood collection. In all sessions that included JUUL products, pods were weighed before and after use and mass of e-liquid aerosolized was calculated; in the ad libitum use condition, the number of cigarettes and IQOS heat sticks used was recorded. All JUUL and IQOS products were used with fully charged batteries and 
unused pods or heat sticks for each use session.

Participants were instructed to inform the study personnel of any adverse events (AE; an untoward medical occurrence associated with use of study products) experienced during the study. AEs were classified by a medically-qualified investigator based on intensity (severity), seriousness, and causal relation to use of study product.

\section{Study Test Products}

Test products included: (1) JUUL $59 \mathrm{mg} / \mathrm{mL}$ nicotine in Classic Tobacco flavor that is commerciallymarketed in the US; (2) JUUL2 Prototype $18 \mathrm{mg} / \mathrm{mL}$ nicotine in tobacco flavor; (3) JUUL2 Prototype 40 $\mathrm{mg} / \mathrm{mL}$ nicotine in tobacco flavor; (4) commercially-available IQOS with Birch tobacco heat sticks $18 \mathrm{mg} / \mathrm{g}$ nicotine; (5) UB combustible cigarette. Like JUUL, the JUUL2 prototype device is inhalation-actuated, does not have any user-modifiable settings, controls, or buttons and includes a temperature control system designed to maintain a consistent operating temperature independent of puff intensity. The JUUL2 prototype pods contained $1.2 \mathrm{~mL}$ of e-liquid (compared to $0.7 \mathrm{~mL}$ in currently-marketed JUULpods) consisting of nicotine (either 18 or $40 \mathrm{mg} / \mathrm{mL}$ ), propylene glycol, glycerol, benzoic acid and flavorants (the same primary ingredients as in currently-marketed JUULpods). The JUUL2 prototypes were designed to produce greater aerosol mass per puff than the currently-marketed JUUL product.

\section{Measures}

\section{Baseline Characteristics}

Participants reported demographic and cigarette smoking characteristics and whether they had ever and currently used ENDS (yes/no).

\section{Subjective Effects}

The 20-item mPES, a psychometrically-validated measure of subjective responses to tobacco products (24) that has previously been used with ENDS including JUUL (25-27), was answered on seven-point response scales from 1 ("Not at all") to 7 ("Extremely"). The mPES included four composite subscales:

"Satisfaction" (4 items), "Psychological Reward" (5 items), "Aversion" (4 items) and "Relief" (5 items).

\section{Data Analysis}

PK parameters included baseline-adjusted maximum plasma nicotine concentration $\left(C_{\text {max-BL }}\right)$ and time to reach maximum plasma nicotine concentration $\left(T_{\max }\right)$; baseline-adjusted total plasma nicotine exposure was calculated using area under the curve (AUC) at 90 minutes in the ad libitum sessions ( $\mathrm{AUC}_{0-90-\mathrm{BL}}$ ) and 60 minutes $\left(\mathrm{AUC}_{0-60-\mathrm{BL}}\right)$ in the controlled use sessions, respectively. A derived pharmacokinetic parameter, the slope of the initial rise in plasma nicotine levels up to $\mathrm{C}_{\max }$, was calculated as $\mathrm{C}_{\max -\mathrm{BL}}$ divided by $T_{\max }(28)$.

All statistical comparisons between test products were conducted separately for the ad libitum and controlled use conditions (the ad libitum and controlled use conditions were of different durations, so are not comparable). To test differences in $\mathrm{C}_{\max -\mathrm{BL}}$ and AUC, values were log-transformed and modeled as dependent variables in linear mixed-effects models with fixed effects of test product, sequence and period and a random participant term. Geometric mean ratios between study products were calculated as back- 
transformed (exponentiated) least-squares ratios with 2-sided 90\% Cls; statistically significant differences in $\mathrm{C}_{\max -\mathrm{BL}}$ and $\mathrm{AUC}$ between test products were indicated if the $90 \%$ confidence intervals $(\mathrm{Cls})$ for geometric mean ratios did not overlap with 1.00 (29). Differences in rate of plasma nicotine rise were tested with mixed-effects models as described above. Differences in $\mathrm{T}_{\max }$ were tested using nonparametric Wilcoxon signed rank tests. Measures of subjective effects (mPES) were analyzed on their original assessment scales using mixed-effects models.

Data were analyzed using IBM SPSS Statistics Version 28 (IBM Corp., Armonk, NY) with alpha level set to 0.05 .

\section{RESULTS}

\section{Participant Accrual and Sample Characteristics}

Out of 112 individuals screened, 40 (35.7\%) met all eligibility criteria, enrolled in the study, were randomized, and completed $\geq 1$ product use session. The most common reasons for ineligibility were positive urine screen for drugs of abuse or alcohol (40.7\%) followed by an excluding medical or psychiatric condition (27.1\%). PK data from 10 total sessions ( 7 ad libitum use and 3 controlled use) were excluded due to multiple missed blood draws. In the ad libitum use session 30 participants completed all five conditions, 4 completed four conditions, 2 completed three conditions, 2 completed two conditions and 2 completed one condition. In the controlled use session 32 participants completed all five conditions, 2 completed four conditions, 2 completed three conditions, 3 completed two conditions and 1 completed one condition. Six participants (15\% of enrolled) were withdrawn from the study prior to completing all product use sessions: three subjects withdrew their consent, two were withdrawn due to an $\mathrm{AE}$, and one was withdrawn by the investigator (see Safety and Tolerability).

The sample (mean age $=43.23$ years $[S D=13.39]$ ) self-reported as $25.0 \%$ female, $85.0 \%$ non-Hispanic White, $10 \%$ non-Hispanic multi-racial, 2.5\% non-Hispanic Asian, 2.5\% non-Hispanic Black. On average, participants reported smoking for 15.88 years $(S D=14.85)$ and currently smoking $16.78(S D=4.32)$ cigarettes per day; $50 \%$ had ever-used ENDS but only 10\% were current ENDS users.

\section{Nicotine Pharmacokinetics}

The time courses of plasma nicotine concentrations following use of each study test product in the ad libitum and controlled use sessions over 90 and 60 minutes, respectively, are displayed in Figures 1 and 2.

\section{Ad Libitum Use}

In the 10-minute ad libitum use session, on average, participants smoked 2.2 cigarettes $(S D=0.49)$ and used 2.3 IQOS heat sticks ( $S D=0.47$ ); participants aerosolized $0.03 \mathrm{~g}$ of e-liquid when using JUUL $59 \mathrm{mg} / \mathrm{mL}$ $(S D=0.01), 0.14 \mathrm{~g}(S D=0.06)$ when using JUUL2 Prototype $18 \mathrm{mg} / \mathrm{mL}$ and $0.11 \mathrm{~g}(S D=0.05)$ when using JUUL2 Prototype $40 \mathrm{mg} / \mathrm{mL}$ (Supplementary Table 1). The highest mean $\mathrm{C}_{\max -\mathrm{BL}}( \pm S D$ ) value was for UB cigarette $(31.66 \pm 21.70 \mathrm{ng} / \mathrm{mL}$; Table 1$)$, which was significantly greater than the $\mathrm{C}_{\max -\mathrm{BL}}$ for IQOS and all JUUL products (Table 2). $C_{\text {max-BL }}$ for JUUL2 Prototype $40 \mathrm{mg} / \mathrm{mL}$ (24.33 17.97 ) was significantly greater than IQOS $(18.22 \pm 9.24 \mathrm{ng} / \mathrm{mL})$ which was, in turn, significantly higher than JUUL2 Prototype $18 \mathrm{mg} / \mathrm{mL}$ $(13.98 \pm 7.97 \mathrm{ng} / \mathrm{mL})$, which was significantly higher than JUUL $59 \mathrm{mg} / \mathrm{mL}(9.25 \pm 4.50 \mathrm{ng} / \mathrm{mL}$; Tables 1-2). 
A similar pattern of results was observed for mean $A U C_{0-90-B L}$ U U cigarette $>$ JUUL2 Prototype $40 \mathrm{mg} / \mathrm{mL}>$ IQOS > JUUL2 Prototype $18 \mathrm{mg} / \mathrm{mL}>$ JUUL $59 \mathrm{mg} / \mathrm{mL}$. Mean rate of plasma nicotine rise for UB cigarettes (3.27 $\pm 3.13 \mathrm{ng} / \mathrm{mL}$ per minute) did not significantly differ from JUUL2 Prototype $40 \mathrm{mg} / \mathrm{mL}(2.59 \pm 2.57$ $\mathrm{ng} / \mathrm{mL}$ per minute) and both were significantly greater than JUUL2 Prototype $18 \mathrm{mg} / \mathrm{mL}(1.33 \pm 0.89 \mathrm{ng} / \mathrm{mL}$ per minute), JUUL $59 \mathrm{mg} / \mathrm{mL}(1.00 \pm 0.88 \mathrm{ng} / \mathrm{mL}$ per minute) and IQOS (1.78 \pm 1.42$)$. Rate of plasma nicotine rise of IQOS was significantly greater than JUUL $59 \mathrm{mg} / \mathrm{mL}$ but did not differ from the JUUL2 Prototype $18 \mathrm{mg} / \mathrm{mL}$. JUUL2 Prototype $18 \mathrm{mg} / \mathrm{mL}$ and JUUL $59 \mathrm{mg} / \mathrm{mL}$ did not significantly differ from each other.

Mean $\mathrm{T}_{\max }$ values for test products ranged from 12.15-15.53 minutes and did not significantly differ (ps>0.37; Table 1).

Figure 1. Mean Baseline-Adjusted Plasma Nicotine Concentrations by Nominal Time in Ad Libitum Use Session

Note. JUUL 59 mg/mL, N=36; JUUL2 Prototype $18 \mathrm{mg} / \mathrm{mL}, \mathrm{N}=35$; JUUL2 Prototype $40 \mathrm{mg} / \mathrm{mL}, \mathrm{N}=36$; IQOS, $\mathrm{N}=38$; UB Cigarette, $\mathrm{N}=33$. 


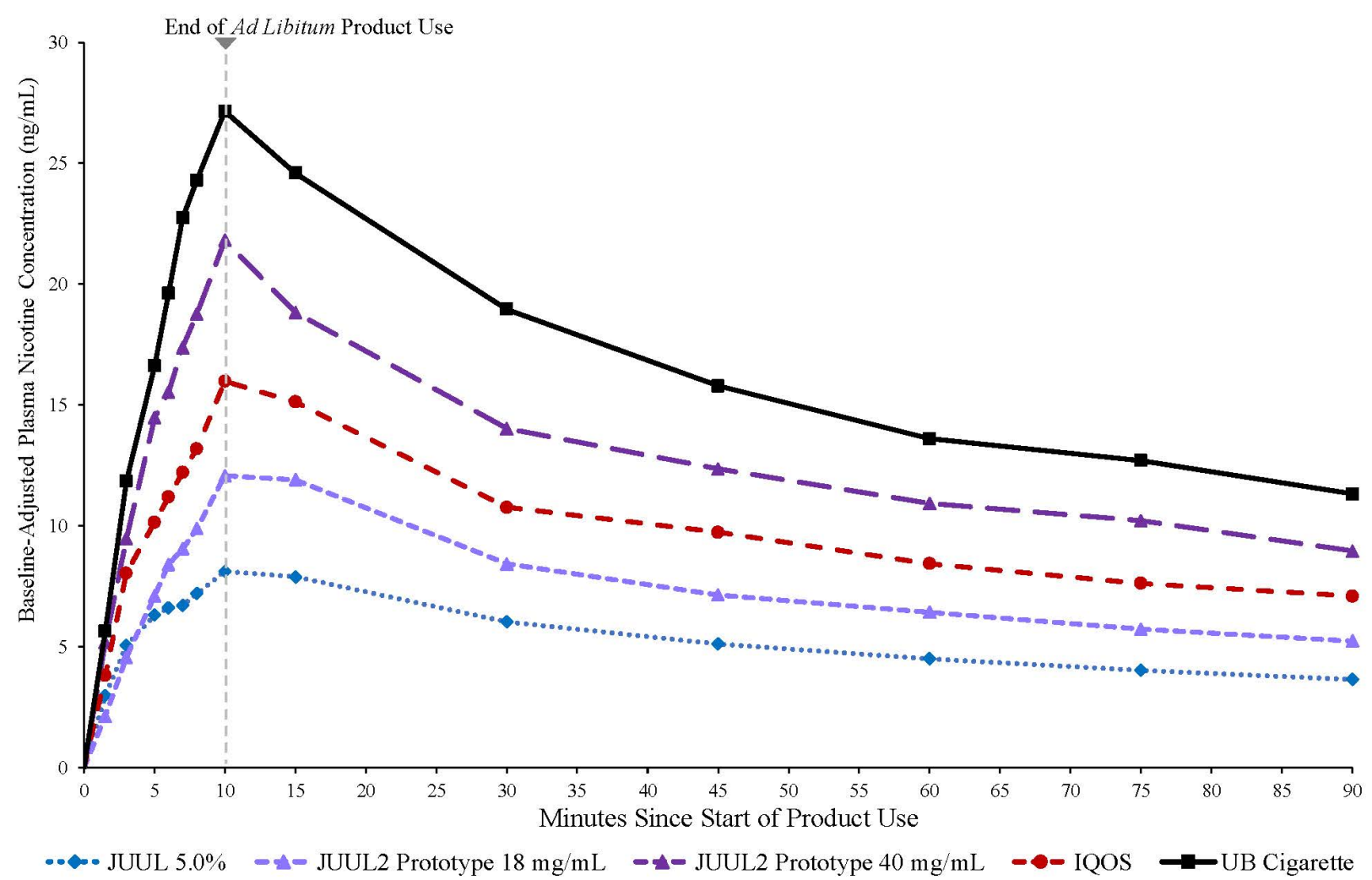

\section{Controlled Use}

In the controlled use session, on average, participants aerosolized $0.02 \mathrm{~g}$ of e-liquid when using JUUL 59 $\mathrm{mg} / \mathrm{mL}(S D=0.004), 0.06 \mathrm{~g}(S D=0.01)$ when using JUUL2 Prototype $18 \mathrm{mg} / \mathrm{mL}$ and $0.06 \mathrm{~g}(S D=0.02)$ when using JUUL2 Prototype $40 \mathrm{mg} / \mathrm{mL}$ (Supplementary Table 1). As in the ad libitum use session, highest mean $\mathrm{C}_{\text {max-BL }}$ was observed for UB cigarettes $(24.83 \pm 13.64 \mathrm{ng} / \mathrm{mL}$; Table 1$)$, which was significantly greater than all JUUL products and IQOS (Table 2). Mean $C_{\max -B L}$ for JUUL2 Prototype $40 \mathrm{mg} / \mathrm{mL}$ (18.42 \pm 12.84 ) did not significantly differ from IQOS (13.68 $\pm 5.58 \mathrm{ng} / \mathrm{mL})$; both were significantly greater than JUUL2 Prototype 18 $\mathrm{mg} / \mathrm{mL}(8.71 \pm 5.08 \mathrm{ng} / \mathrm{mL})$ and JUUL $59 \mathrm{mg} / \mathrm{mL}(9.77 \pm 9.31 \mathrm{ng} / \mathrm{mL})$, which did not significantly differ. Similarly, mean $\mathrm{AUC}_{0-60-B L}$ for UB cigarettes was significantly greater than all JUUL and IQOS products. $\mathrm{AUC}_{0-60-\mathrm{BL}}$ for JUUL2 Prototype $40 \mathrm{mg} / \mathrm{mL}$ did not significantly differ from IQOS and both were significantly greater than JUUL $59 \mathrm{mg} / \mathrm{mL}$ and JUUL2 Prototype $18 \mathrm{mg} / \mathrm{mL}$, which did not significantly differ. Mean rate of plasma nicotine rise for UB cigarettes $(4.16 \pm 3.10 \mathrm{ng} / \mathrm{mL}$ per minute) did not significantly differ from JUUL2 Prototype $40 \mathrm{mg} / \mathrm{mL}(3.24 \pm 3.17 \mathrm{ng} / \mathrm{mL}$ per minute) but was significantly greater than

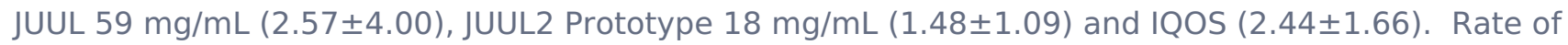


plasma nicotine rise for JUUL2 Prototype $40 \mathrm{mg} / \mathrm{mL}$ was significantly greater than JUUL2 Prototype 18 $\mathrm{mg} / \mathrm{mL}$, and JUUL $59 \mathrm{mg} / \mathrm{mL}$ and IQOS products did not significantly differ from each other. Mean $T_{\max }$ ranged from 6.13-9.52 minutes and did not significantly differ across products ( $p s>0.08$ ).

Figure 2. Mean Baseline-Adjusted Plasma Nicotine Concentrations by Nominal Time in Controlled Use Session

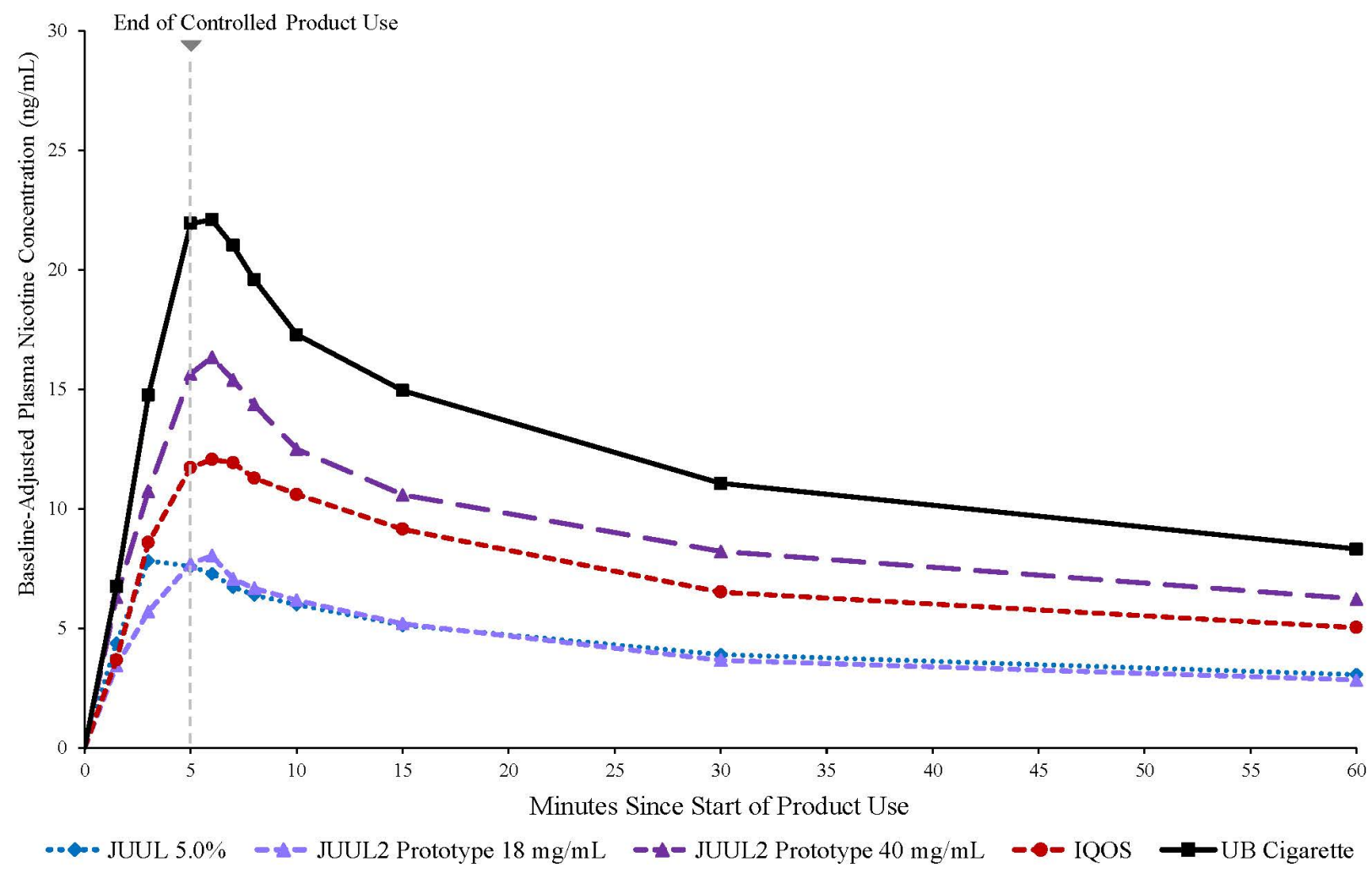

Note. JUUL 59 mg/mL, N=36; JUUL2 Prototype $18 \mathrm{mg} / \mathrm{mL}, \mathrm{N}=35$; JUUL2 Prototype $40 \mathrm{mg} / \mathrm{mL}, \mathrm{N}=36$; IQOS, $\mathrm{N}=38$; UB Cigarette, $\mathrm{N}=33$.

\section{Subjective Effects}

Mean scores on the mPES "Satisfaction" subscale, in both ad libitum and controlled use conditions, were significantly higher for UB cigarettes than for all JUUL and IQOS products (Figure 3, Panels A and E). In both ad libitum and controlled conditions, JUUL $59 \mathrm{mg} / \mathrm{mL}$ and both JUUL2 prototypes were rated significantly more satisfying than IQOS; in the ad libitum condition (but not controlled) the JUUL2 Prototype $18 \mathrm{mg} / \mathrm{mL}$ was rated significantly more satisfying than JUUL $59 \mathrm{mg} / \mathrm{mL}$. JUUL2 Prototype $40 \mathrm{mg} / \mathrm{mL}$ and JUUL 59 
$\mathrm{mg} / \mathrm{mL}$ did not significantly differ in either use condition (Supplementary Table 2).

On the "Relief" subscale, mean scores for UB cigarettes was significantly higher than all other products in both ad libitum and controlled conditions (Figure 3, Panels B and F). In the ad libitum condition both JUUL2 prototypes were rated significantly higher than JUUL $59 \mathrm{mg} / \mathrm{mL}$ and IQOS, which did not significantly differ from each other. In the controlled use condition both JUUL2 prototypes were rated significantly higher than IQOS, and the JUUL2 Prototype $40 \mathrm{mg} / \mathrm{mL}$ was significantly greater than JUUL2 Prototype $18 \mathrm{mg} / \mathrm{mL}$ and JUUL $59 \mathrm{mg} / \mathrm{mL}$.

On the "Psychological Reward" subscale, mean scores for UB cigarette was significantly higher than all other products in ad libitum and controlled conditions (Figure 3, Panels C and G). In the ad libitum condition both JUUL2 prototypes were rated significantly higher than IQOS and JUUL $59 \mathrm{mg} / \mathrm{mL}$; IQOS and JUUL $59 \mathrm{mg} / \mathrm{mL}$ did not significantly differ. In the controlled use condition all JUUL products were rated significantly higher than IQOS.

On the "Aversion" subscale, in the ad libitum use condition mean scores for JUUL $59 \mathrm{mg} / \mathrm{mL}$ and JUUL2 Prototype $18 \mathrm{mg} / \mathrm{mL}$ were significantly lower than JUUL2 Prototype $40 \mathrm{mg} / \mathrm{mL}$, IQOS and UB cigarette, which did not significantly differ from each other (Figure 3, Panel D). In the controlled use condition JUUL2 Prototype $40 \mathrm{mg} / \mathrm{mL}$ was rated significantly more aversive than all other test products; JUUL $59 \mathrm{mg} / \mathrm{mL}$ and JUUL2 Prototype $18 \mathrm{mg} / \mathrm{mL}$ were rated significantly lower than IQOS (Figure 3, Panel H).

Figure 3. mPES Composite Subscale Scores among Test Products in Ad Libitum and Controlled Use Sessions (Mean $\pm S E$ ) 


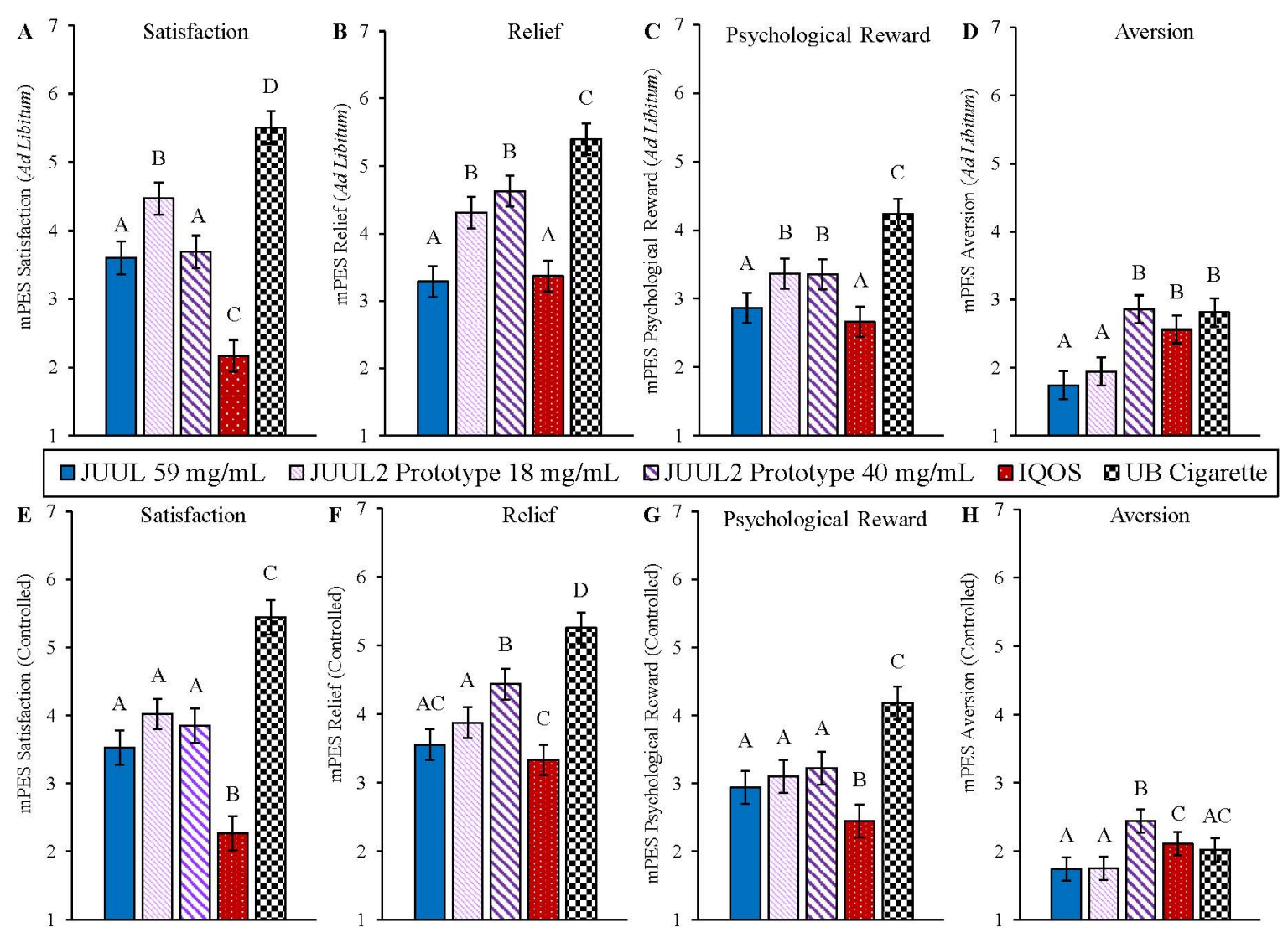

Note. Abbreviations: mPES, Modified Product Evaluation Scale; SE, Standard error.

JUUL, N=36; JUUL2 Prototype 18 mg/mL, N=37; JUUL2 Prototype 40 mg/mL, N=37; IQOS, N=38; UB Cigarette, $\mathrm{N}=37$.

Test products that do not share the same letter significantly differ $(p<0.05)$. Values represent marginal means from mixed-effects models.

\section{Safety and Tolerability}

There were no serious AEs reported in this study (Supplementary Table 3). All AEs were considered mild or moderate except for one severe AE in the UB cigarette condition (syncope). Two participants were discontinued due to AEs: one after using JUUL2 Prototype $40 \mathrm{mg} / \mathrm{mL}$ (allergic reaction; mild severity and judged possibly-related to product use) and one after using IQOS (infected insect bites; mild severity and judged not related to product use). The largest proportion of participants reported an AE after use of JUUL2 Prototype $40 \mathrm{mg} / \mathrm{mL}$ (32.4\%) followed by UB cigarette (29.7\%), JUUL $59 \mathrm{mg} / \mathrm{mL}$ (19.4\%), IQOS (15.8\%) and JUUL2 Prototype $18 \mathrm{mg} / \mathrm{mL}$ (13.5\%). The proportion of AEs considered possibly or likely related to product use was highest for the JUUL2 Prototype $40 \mathrm{mg} / \mathrm{mL}$ (32.4\%) followed by UB cigarette (21.6\%), IQOS (10.5\%), JUUL (5.6\%) and JUUL2 Prototype $18 \mathrm{mg} / \mathrm{mL}$ (5.4\%). 
The most commonly-reported AEs were dizziness (27.5\%), nausea (15.0\%), procedural dizziness related to blood draw (10.0\%), vomiting (7.5\%) and cough (7.5\%). These AEs were most commonly reported in the JUUL2 Prototype $40 \mathrm{mg} / \mathrm{mL}$ condition (12 reports of these symptoms); they were less commonly reported in other conditions (UB cigarette, 7 reports; IQOS, 7 reports; JUUL 59 mg/mL, 2 reports; JUUL2 Prototype 18 $\mathrm{mg} / \mathrm{mL}, 2$ reports).

\section{DISCUSSION}

In this laboratory study, nicotine delivery was greatest for UB cigarettes, followed by use of JUUL2 Prototype $40 \mathrm{mg} / \mathrm{mL}$, IQOS, JUUL2 Prototype $18 \mathrm{mg} / \mathrm{mL}$ and JUUL $59 \mathrm{mg} / \mathrm{mL}$, in that order. None of the JUUL or IQOS products delivered as much nicotine or were rated as satisfying as a combustible cigarette. However, among the JUUL and IQOS test products, subjective satisfaction was not always directly related to nicotine delivery: JUUL2 Prototype $18 \mathrm{mg} / \mathrm{mL}$ delivered less nicotine than JUUL2 Prototype 40 $\mathrm{mg} / \mathrm{mL}$ and IQOS but was rated as significantly more satisfying and less aversive.

The ability of noncombustible alternative nicotine-delivery products to provide satisfying effects to adult smokers is central to facilitating switching: subjective satisfaction from ENDS use is associated with continued ENDS use and switching away from smoking (25, 30-32). Evidence from controlled laboratory studies suggests a relationship between nicotine dose and reinforcing effects $(33,34)$, but increased nicotine is also sometimes associated with orosensory harshness and irritancy (35-37), and data on the effect of nicotine delivery from ENDS on subjective satisfaction is mixed (38-40). Although JUUL $59 \mathrm{mg} / \mathrm{mL}$ delivered significantly less nicotine than IQOS, it was rated significantly higher on MPES "Satisfaction" subscale and lower on "Aversion" subscale; similarly, the JUUL2 Prototype $18 \mathrm{mg} / \mathrm{mL}$ was rated as more satisfying and less aversive than JUUL2 Prototype $40 \mathrm{mg} / \mathrm{mL}$, despite delivering less nicotine.

Regulatory initiatives that limit the maximum nicotine concentration in ENDS to $20 \mathrm{mg} / \mathrm{mL}$, such as the European Union Tobacco Products Directive, state that this concentration allows for nicotine delivery that is comparable to the amount of nicotine derived from smoking a combustible cigarette (15). PK data demonstrates that JUUL with $18 \mathrm{mg} / \mathrm{mL}$ delivers approximately one-fifth of the nicotine delivered by a cigarette, and that JUUL $59 \mathrm{mg} / \mathrm{mL}$, compared to $18 \mathrm{mg} / \mathrm{mL}$, more effectively reduces withdrawal symptoms and craving for cigarettes (7, 16). Accordingly, it was concluded that the 18 (vs. 59) mg/mL JUUL product may have more limited potential in helping heavier and dependent adult smokers switch away from smoking $(7,16)$. Consistent with this, an observational comparative study of JUUL users in the UK (predominantly $18 \mathrm{mg} / \mathrm{mL}$ ) and users in the US and Canada (predominantly $59 \mathrm{mg} / \mathrm{mL}$ ), matched on demographics and smoking profile, showed that switching rates were significantly higher among adult smokers using the higher-nicotine-concentration JUUL product (14).

The association of ENDS nicotine concentration and nicotine delivery is not monotonic, as other parameters such as aerosol volume moderate the relation $(17,41)$. Consistent with their design, the JUUL2 prototypes evaluated in this study produced significantly greater aerosol mass than JUUL $59 \mathrm{mg} / \mathrm{mL}$. In the ad libitum use condition, the JUUL2 Prototype $18 \mathrm{mg} / \mathrm{mL}$ delivered significantly more nicotine than JUUL 59 
$\mathrm{mg} / \mathrm{mL}$ but less nicotine than a cigarette. JUUL2 Prototype $18 \mathrm{mg} / \mathrm{mL}$ was also rated as more satisfying and more effective at reducing cigarette craving and withdrawal symptoms than JUUL $59 \mathrm{mg} / \mathrm{mL}$ and IQOS, but lower than a cigarette. Hence, an ENDS product based on JUUL2 Prototype $18 \mathrm{mg} / \mathrm{mL}$ may facilitate increased switching among adult smokers.

PK and subjective data from laboratory studies indicates that the abuse liability of JUUL $59 \mathrm{mg} / \mathrm{mL}$ is lower than combustible cigarettes $(8,26,27)$. Additionally, real-world longitudinal evidence demonstrates that among smokers who switch to JUUL, levels of JUUL dependence are significantly lower than smokers' prior cigarette dependence $(42,43)$. The PK and subjective effect profiles observed herein indicate that the pharmacological abuse liability of all of the JUUL and IQOS products evaluated is lower than that of cigarettes. Given that indices commonly used to characterize abuse liability, such as subjective satisfaction, are also important for facilitating switching away from smoking $(30,31)$, some degree of abuse liability is deemed necessary for noncombustible products to successfully compete with cigarettes (10-12).

The JUUL2 Prototype $40 \mathrm{mg} / \mathrm{mL}$ was rated significantly more aversive than both JUUL $59 \mathrm{mg} / \mathrm{mL}$ and JUUL2 Prototype $18 \mathrm{mg} / \mathrm{mL}$. Further, the adverse event data indicate a trend towards more dizziness and nausea for the JUUL2 Prototype $40 \mathrm{mg} / \mathrm{mL}$. These findings suggest that, as currently designed and formulated, JUUL2 Prototype $40 \mathrm{mg} / \mathrm{mL}$ is not an optimal product for adult smokers. Further evolution and modification of this prototype will be needed to achieve a favorable product profile to support switching. In contrast, the JUUL2 $18 \mathrm{mg} / \mathrm{mL}$ prototype produced notably greater satisfaction and less aversion, suggesting the potential to be refined into a product with limited nicotine concentration that could be useful for helping smokers switch away from cigarettes.

Strengths of the study include the evaluation of commonly-used HTP and ENDS products, randomized within-subjects design, use of both ad libitum and controlled use procedures and confinement of participants to a clinical laboratory setting to monitor and control nicotine/tobacco product use. Limitations include the open-label design which may have allowed pre-existing expectations to affect subjective responses. History of HTP use was not assessed, and it is unknown if participants had experience using HTPs. Additionally, the study only assessed JUUL2 prototypes with tobacco flavors, and future research is needed to assess the PK and subjective effects of non-tobacco flavors when used in similar JUUL2 devices. Furthermore, the JUUL2 products evaluated were developmental prototypes, and may differ from ENDS products that will be marketed to smokers.

\section{CONCLUSIONS}

In this sample of adult smokers, all evaluated JUUL and IQOS products delivered less nicotine than UB cigarettes. IQOS delivered more nicotine than JUUL2 Prototype $18 \mathrm{mg} / \mathrm{mL}$ and JUUL $59 \mathrm{mg} / \mathrm{mL}$, but JUUL products were generally rated as more satisfying and more effective at reducing craving than IQOS-the JUUL2 Prototype $18 \mathrm{mg} / \mathrm{mL}$ and JUUL $59 \mathrm{mg} / \mathrm{mL}$ were also less aversive than IQOS. Use of JUUL $59 \mathrm{mg} / \mathrm{mL}$ and JUUL2 Prototype $18 \mathrm{mg} / \mathrm{mL}$ was well tolerated under both use conditions, whereas the JUUL2 Prototype $40 \mathrm{mg} / \mathrm{mL}$ generated some aversive responses. JUUL2 Prototype $18 \mathrm{mg} / \mathrm{mL}$ may provide a basis for future 
ENDS products that can facilitate increased switching among adult smokers.

\section{REFERENCES}

1. US Department of Health and Human Services (2014) The health consequences of smoking-50 years of progress: a report of the Surgeon General. Department of Health and Human Services, Public Health Service, Office of the Surgeon General. US. In: Government Printing Office, Washington, D.C.

2. Benowitz NL. Nicotine addiction. N Engl J Med. 2010;362(24):2295-303.

3. Gottlieb S, Zeller M. A Nicotine-Focused Framework for Public Health. N Engl J Med. 2017;377(12):11114.

4. Akiyama Y, Sherwood N. Systematic review of biomarker findings from clinical studies of electronic cigarettes and heated tobacco products. Toxicol Rep. 2021; 8:282-294.

5. National Academies of Sciences, Engineering, and Medicine 2018. Public Health

Consequences of E-Cigarettes. Washington, DC: The National Academies Press.

https://doi.org/10.17226/24952.

6. Mallock N, Pieper E, Hutzler C, Henkler-Stephani F, Luch A. Heated Tobacco Products: A Review of Current Knowledge and Initial Assessments. Front Public Health. 2019;7:287.

7. Phillips-Waller A, Przulj D, Pesola F, Myers Smith K, Hajek P. Nicotine delivery and user ratings of IQOS heated tobacco system compared to cigarettes, Juul and refillable e-cigarettes. Nicotine Tob Res. 2021; ntab094. doi: 10.1093/ntr/ntab094.

8. Maloney S, Eversole A, Crabtree M, Soule E, Eissenberg T, Breland A. Acute effects of JUUL and IQOS in cigarette smokers. Tob Control. 2020; tobaccocontrol-2019-055475. doi: 10.1136/tobaccocontrol-2019055475.

9. Buchhalter AR, Goldenson NI, Kim E, Chan S, Cohen G, Henningfield JE. Pharmacokinetics and Subjective Eects of the JL Electronic Nicotine Delivery System (ENDS) Compared to Five ENDS, a Heated Tobacco Product, and a Combustible Cigarette. College for Problems on Drug Dependence; Hollywood, FL, 2020. 10. Abrams DB, Glasser AM, Pearson JL, Villanti AC, Collins LK, Niaura RS. Harm Minimization and Tobacco Control: Reframing Societal Views of Nicotine Use to Rapidly Save Lives. Annu Rev Public Health. 2018;39:193-213.

11. Abrams DB, Glasser AM, Villanti AC, Pearson JL, Rose S, Niaura RS. Managing nicotine without smoke to save lives now: Evidence for harm minimization. Prev Med. 2018;117:88-97.

12. Food and Drug Administration (2020) Technical Project Lead review - IQOS tobacco heating system. Silver Spring, MD: FDA; 2019. https://www.fda.gov/me- dia/139796/download. Published July 7, 2020. Accessed June 17, 2021.

13. Cobb CO, Foulds J, Yen M-S, Veldheer S, Lopez AA, Yingst JM, et al. Effect of an electronic nicotine delivery system with 0,8 , or $36 \mathrm{mg} / \mathrm{mL}$ liquid nicotine versus a cigarette substitute on tobacco-related toxicant exposure: a four-arm, parallel-group, randomised, controlled trial. The Lancet Respiratory Medicine. 2021; 9(8):840-850. 
14. Goldenson NI, Ding Y, Prakash S, Hatcher C, Augustson EM, Shiffman S. Differences in Switching Away From Smoking Among Adult Smokers Using JUUL Products in Regions With Different Maximum Nicotine Concentrations: North America and the United Kingdom. N Nicotine Tob Res. 2021;ntab062. doi: 10.1093/ntr/ntab062.

15. The European Parliament and the Council of the European Union (2014). The approximation of the laws, regulations and administrative provisions of the Member States concerning the manufacture, presentation and sale of tobacco and related products and repealing Directive 2001/37/EC. In: The European Parliament and the Council of the European Union, ed. Official Journal of the European Union. https://eur-lex.europa.eu/legal-content/en/TXT/?uri=CELEX\%3A32014L0040. Accessed September 7, 2021. 16. Goldenson NI, Fearon IM, Buchhalter AR, Heningfield JE. An Open-Label, Randomised, Controlled, Crossover Study to Assess Nicotine Pharmacokinetics and Subjective Effects of the JUUL System with Three Nicotine Concentrations Relative to Combustible Cigarettes in Adult Smokers. Nicotine Tob Res. 2021; 23(6):947-955.

17. Jacobson K, Martinez J, Larroque S, Jones IW, Paschke T. Nicotine pharmacokinetics of electronic cigarettes: A pooled data analysis from the literature. Toxicol Rep. 2021;8:84-95.

18. Leventhal AM, Mason TB, Kirkpatrick MG, Anderson MK, Levine MD. E-cigarette device power moderates the effects of non-tobacco flavors and nicotine on product appeal in young adults. Addict Behav. 2020;107:106403.

19. Floyd EL, Queimado L, Wang J, Regens JL, Johnson DL. Electronic cigarette power affects count concentration and particle size distribution of vaping aerosol. PLoS One. 2018;13(12):e0210147.

20. Kosmider L, Spindle TR, Gawron M, Sobczak A, Goniewicz ML. Nicotine emissions from electronic cigarettes: Individual and interactive effects of propylene glycol to vegetable glycerin composition and device power output. Food Chem Toxicol. 2018;115:302-5.

21. Peace MR, Mulder HA, Baird TR, Butler KE, Friedrich AK, Stone JW, et al. Evaluation of Nicotine and the Components of e-Liquids Generated from e-Cigarette Aerosols. J J Anal Toxicol. 2018;42(8):537-43.

22. Talih S, Balhas Z, Eissenberg T, Salman R, Karaoghlanian N, El Hellani A, et al. Effects of User Puff Topography, Device Voltage, and Liquid Nicotine Concentration on Electronic Cigarette Nicotine Yield: Measurements and Model Predictions. Nicotine Tob Res. 2014;17(2):150-7.

23. Ebajemito JK, McEwan M, Gale N, Camacho OM, Hardie G, Proctor CJ. A randomised controlled singlecentre open-label pharmacokinetic study to examine various approaches of nicotine delivery using electronic cigarettes. Sci Rep. 2020;10(1):19980.

24. Hatsukami DK, Zhang Y, O'Connor RJ, Severson HH. Subjective responses to oral tobacco products: scale validation. Nicotine Tob Res. 2013;15(7):1259-64.

25. Gades MS, Petersen A, Meier E, Lindgren BR, O'Connor RJ, Shields PG, et al. The role of subjective responses in electronic cigarette uptake and substitution in adult smokers. Drug Alcohol Depend. 2020;212:107999.

26. Goldenson NI, Buchhalter AR, Augustson EM, Rubinstein ML, Henningfield JE. Abuse liability 
assessment of the JUUL system in four flavors relative to combustible cigarette, nicotine gum and a comparator electronic nicotine delivery system among adult smokers. Drug and Alcohol Dependence. 2020;217:108395.

27. Goldenson NI, Buchhalter AR, Augustson EM, Rubinstein ML, Van Hoof D, Henningfield JE. Abuse liability assessment of the JUUL system in two nicotine concentrations compared to combustible cigarette, nicotine gum and comparator electronic nicotine delivery system. Drug Alcohol Depend. 2020;217:108441. 28. de Wit H, Bodker B, Ambre J. Rate of increase of plasma drug level influences subjective response in humans. Psychopharmacology (Berl). 1992;107(2-3):352-8.

29. Food and Drug Administration (2001) Guidance for industry: Statistical approaches to establishing bioequivalence. FDA, Washington, DC. https://www.fda.gov/media/70958/download. Published January, 2021. Accessed June 17, 2021.

30. Goldenson NI, Shiffman S, Hatcher H, Lamichhane D, Gaggar A, Le GM, et al. Switching away from Cigarettes across 12 Months among Adult Smokers Purchasing the JUUL System. American Journal of Health Behavior. 2021;45(3):443-63.

31. Evans AT, Henderson KC, Geier A, Weaver SR, Spears CA, Ashley DL, et al. What Motivates Smokers to Switch to ENDS? A Qualitative Study of Perceptions and Use. Int J Environ Res Public Health. 2020;17(23). 32. Pearson JL, Zhou Y, Smiley SL, Rubin LF, Harvey E, Koch B, et al. Intensive longitudinal study of the relationship between cigalike e-cigarette use and cigarette smoking among adult cigarette smokers without immediate plans to quit smoking. Nicotine Tob Res. 2020;23(3):527-534.

33. Kalman D. The subjective effects of nicotine: methodological issues, a review of experimental studies, and recommendations for future research. Nicotine Tob Res. 2002;4(1):25-70.

34. Kalman D, Smith SS. Does nicotine do what we think it does? A meta-analytic review of the subjective effects of nicotine in nasal spray and intravenous studies with smokers and nonsmokers. Nicotine Tob Res. 2005; 7(3):317-33.

35. Hummel T, Livermore A, Hummel C, Kobal G. Chemosensory event-related potentials in man: relation to olfactory and painful sensations elicited by nicotine. Electroencephalography and Clinical Neurophysiology/Evoked Potentials Section. 1992;84(2):192-5.

36. Carstens E E, Carstens MI. Sensory effects of nicotine and tobacco. Nicotine Tob Res. 2021; ntab086. doi: 10.1093/ntr/ntab086.

37. Caldwell B, Sumner W, Crane J. A systematic review of nicotine by inhalation: is there a role for the inhaled route? Nicotine Tob Res. 2012;14(10):1127-39.

38. Dawkins L, Cox S, Goniewicz M, McRobbie H, Kimber C, Doig M, et al. 'Real-world' compensatory behaviour with low nicotine concentration e-liquid: subjective effects and nicotine, acrolein and formaldehyde exposure. Addiction. 2018;113(10):1874-82.

39. Maloney SF, Breland A, Soule EK, Hiler M, Ramôa C, Lipato T, et al. Abuse liability assessment of an electronic cigarette in combustible cigarette smokers. Experimental and Clinical Psychopharmacology. 2019;27(5):443-54. 
40. Leventhal AM, Goldenson NI, Barrington-Trimis JL, Pang RD, Kirkpatrick MG. Effects of non-tobacco flavors and nicotine on e-cigarette product appeal among young adult never, former, and current smokers. Drug Alcohol Depend. 2019;203:99-106.

41. Benowitz NL, St.Helen G, Liakoni E. Clinical Pharmacology of Electronic Nicotine Delivery Systems (ENDS): Implications for Benefits and Risks in the Promotion of the Combusted Tobacco Endgame. The Journal of Clinical Pharmacology. 2021;61(S2):S18-S36.

42. Leavens ELS, Nollen N, Ahluwalia JS, Mayo MS, Rice M, Brett El, et al. Changes in dependence, withdrawal, and craving among adult smokers who switch to nicotine salt pod-based e-cigarettes. Addiction. 2021; doi: 10.1111/add.15597.

43. Shiffman S, Goldenson NI, Hatcher C, Augustson EM. Changes in Dependence as Smokers Switch from Cigarettes to JUUL in Two Nicotine Concentrations. Am J Health Behav. 2021;45(3):563-75.

Table 1. PK Parameters of Test Products in Controlled and Ad Libitum Use Sessions 


\begin{tabular}{|c|c|c|c|c|c|}
\hline PK Parameter & JUUL 5.0\% & $\begin{array}{l}\text { JUUL2 Prototype } \\
18 \mathrm{mg} / \mathrm{mL}\end{array}$ & $\begin{array}{l}\text { JUUL2 Prototype } \\
40 \mathrm{mg} / \mathrm{mL}\end{array}$ & IQOS & UB Cigarette \\
\hline \multicolumn{6}{|l|}{ Ad Libitum Use } \\
\hline \multicolumn{6}{|c|}{$C_{\max -B L}(n g / m L)$} \\
\hline Mean $(S D)$ & $9.25(4.50)^{\mathrm{a}}$ & $13.98(7.97)^{\mathrm{b}}$ & $24.33(17.97)^{c}$ & $18.22(9.24)^{d}$ & $31.66(21.70)^{\mathrm{e}}$ \\
\hline Median & 8.59 & 13.93 & 20.40 & 17.18 & 24.45 \\
\hline \multicolumn{6}{|c|}{$A \cup C_{0-90-B L}(\mathrm{ng} \times \mathrm{min} / \mathrm{mL})$} \\
\hline Mean (SD) & $478.35(227.35)^{\mathrm{a}}$ & $686.95(333.93)^{b}$ & $1150.90(632.11)^{c}$ & $892.98(330.19)^{d}$ & $1472.84(666.59)^{\mathrm{e}}$ \\
\hline Median & 401.57 & 691.44 & 1121.58 & 905.74 & 1370.76 \\
\hline \multicolumn{6}{|c|}{ Rate of Plasma Nicotine Rise ( $\mathrm{ng} / \mathrm{mL}$ per Minute) } \\
\hline Mean (SD) & $1.00(0.88)^{\mathrm{a}}$ & $1.33(0.89)^{\mathrm{ab}}$ & $2.59(2.57)^{C}$ & $1.78(1.42)^{\mathrm{b}}$ & $3.27(3.13)^{c}$ \\
\hline Median & 0.75 & 1.06 & 1.95 & 1.44 & 2.34 \\
\hline \multicolumn{6}{|l|}{$\mathrm{T}_{\max }$ (mins) } \\
\hline Mean $(S D)$ & $12.50(6.06)^{\mathrm{a}}$ & $12.15(4.34)^{\mathrm{a}}$ & $12.30(7.08)^{\mathrm{a}}$ & $15.53(13.28)^{\mathrm{a}}$ & $12.51(6.79)^{\mathrm{a}}$ \\
\hline Median & 14.92 & 10.13 & 10.00 & 10.08 & 10.00 \\
\hline \multicolumn{6}{|l|}{ Controlled Use } \\
\hline \multicolumn{6}{|c|}{$\mathrm{C}_{\max -\mathrm{BL}}(\mathrm{ng} / \mathrm{mL})$} \\
\hline Mean $(S D)$ & $9.77(9.31)^{a}$ & $8.71(5.08)^{\mathrm{a}}$ & $18.42(12.84)^{b}$ & $13.68(5.58)^{\mathrm{b}}$ & $24.83(13.64)^{c}$ \\
\hline Median & 7.55 & 7.23 & 14.64 & 12.55 & 22.68 \\
\hline \multicolumn{6}{|c|}{$A \cup C_{0-60-B L}(n g \times m i n / m L)$} \\
\hline Mean $(S D)$ & $268.44(99.18)^{a}$ & $249.96(93.15)^{a}$ & $531.59(260.72)^{\mathrm{b}}$ & $433.18(130.73)^{\mathrm{b}}$ & $726.16(304.70)^{c}$ \\
\hline Median & 272.90 & 260.37 & 510.16 & 436.67 & 699.61 \\
\hline \multicolumn{6}{|c|}{ Rate of Plasma Nicotine Rise ( $\mathrm{ng} / \mathrm{mL}$ per Minute) } \\
\hline Mean (SD) & $2.57(4.00)^{\mathrm{ab}}$ & $1.48(1.09)^{\mathrm{a}}$ & $3.24(3.17)^{\mathrm{bc}}$ & $2.44(1.66)^{\mathrm{ab}}$ & $4.16(3.10)^{c}$ \\
\hline Median & 1.17 & 1.11 & 2.31 & 1.89 & 3.27 \\
\hline \multicolumn{6}{|l|}{$T_{\max }$ (mins) } \\
\hline Mean (SD) & $6.13(2.83)^{\mathrm{a}}$ & $6.56(2.04)^{a}$ & $8.02(9.05)^{a}$ & $6.98(2.91)^{a}$ & $9.52(10.54)^{a}$ \\
\hline Median & 6.02 & 6.03 & 6.00 & 6.52 & 6.39 \\
\hline
\end{tabular}

Note. Abbreviations: $\mathrm{AUC}_{-\mathrm{BL}}$, baseline-adjusted area under the curve; $\mathrm{C}_{\max -\mathrm{BL}}$, baseline-adjusted maximum plasma nicotine concentration; SD, standard deviation; $\mathrm{T}_{\max }$, time to maximum plasma nicotine concentration; UB, usual brand.

JUUL, N=35; JUUL2 Prototype $18 \mathrm{mg} / \mathrm{mL}, \mathrm{N}=37$; JUUL2 Prototype $40 \mathrm{mg} / \mathrm{mL}, \mathrm{N}=37$; IQOS, N=38; UB Cigarette, $\mathrm{N}=34$.

Test product means in the same row that do not share superscripts significantly differ $(p<0.05$ or geometric mean ratio and associated 90\% confidence interval does not overlap with 1.00).

Table 2. Geometric Mean Ratios of $C_{m a x-B L}$ and $A U C_{0-90-B L}$ or $A U C_{0-60-B L}$ among Test Products in Controlled and Ad Libitum Use 


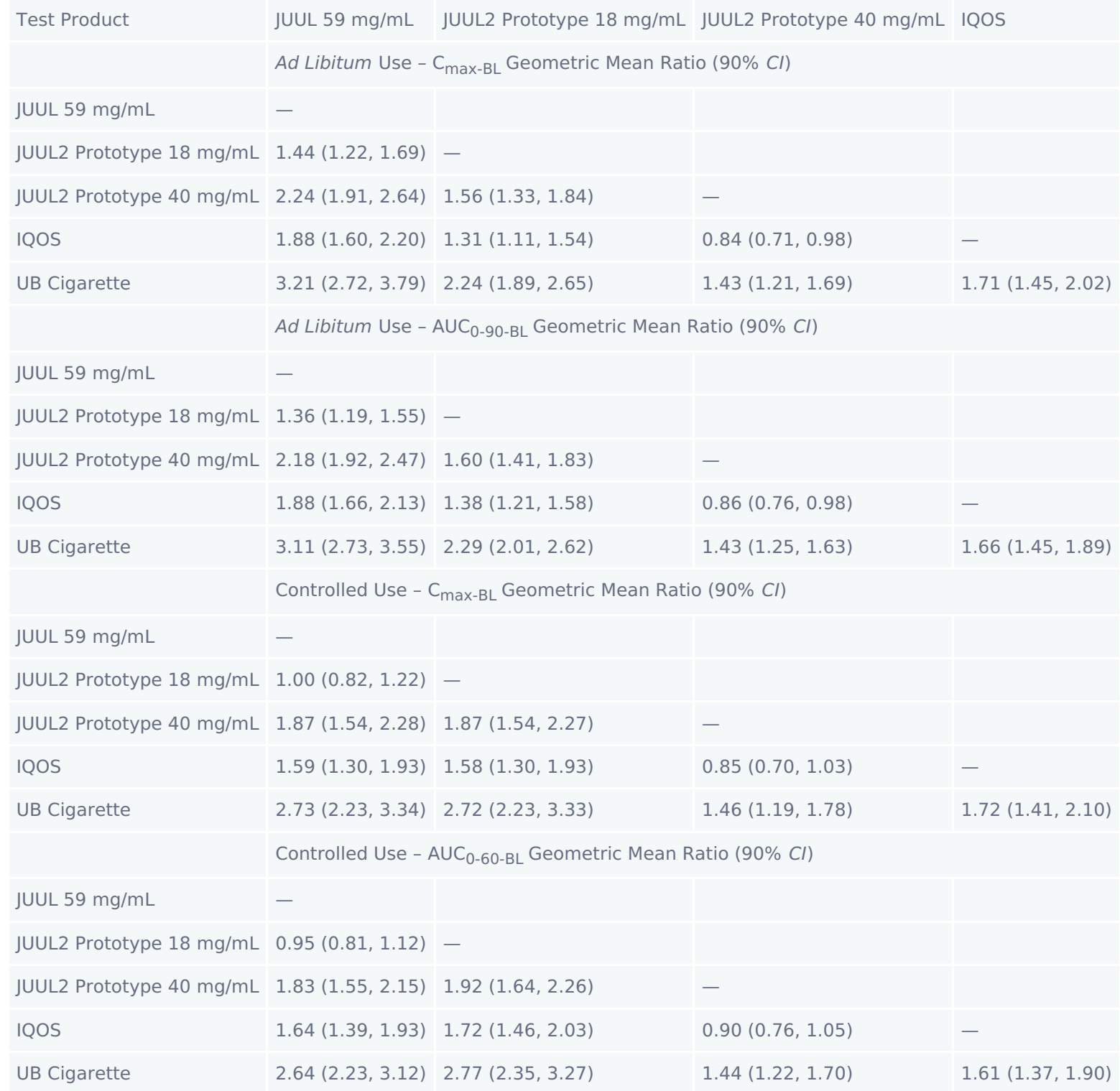

Note. JUUL, N=35; JUUL2 Prototype $18 \mathrm{mg} / \mathrm{mL}, \mathrm{N}=37$; JUUL2 Prototype $40 \mathrm{mg} / \mathrm{mL}, \mathrm{N}=37$; IQOS, N=38; UB Cigarette, $\mathrm{N}=34$.

Abbreviations: $A \cup C_{-B L}$, baseline-adjusted area under the curve; $\mathrm{Cl}$, confidence interval, $\mathrm{C}_{\text {max- } \mathrm{BL}}$, baselineadjusted maximum plasma nicotine concentration; UB, usual brand.

Values represent geometric mean ratios (Comparator Product [Row] $\div$ Test Product [Column]) and 90\% Cls.

Point estimates and 2-sided $90 \% \mathrm{Cls}$ for the geometric mean ratios were derived from back-transformed (exponentiated) least-squares coefficients of mean product differences from mixed-effects models with fixed effects of test product, period, sequence and participant included as a random effect. 